\title{
HIGH FREQUENCY SOFT SWITCHING PWM DC/DC CONVERTER WITH SECONDARY SIDE ACTIVE RECTIFIER
}

\author{
Róbert ŽATKOVIČ* Jaroslav DUDRIK*, Daniel TRIP** \\ *Department of Electrical Engineering and Mechatronics, Faculty of Electrical Engineering and Informatics, \\ Technical University of Košice, Letná 9, 04200 Košice, Slovak Republic, Tel.: +421 55602 2283, E-mail: robert.zatkovic@tuke.sk \\ ${ }^{* *}$ Department of Electronics and Telecommunications, Faculty of Electrical Engineering and Information Technology, \\ University of Oradea, Universitatii 1, 410087 Oradea, Romania, Tel.: +402 59408 194, E-mail: dtrip@uoradea.ro
}

\begin{abstract}
A paper is dedicated to presentation of research process of new type of high frequency soft switching DC/DC converter. In the first section of paper, a short introduction to research task and overview of published solutions is done. In the second section of paper, an already solved part of research task is briefly described. In the third section of paper, a description of currently solved part of research task is done and key research results are presented. In the last section of paper, future steps of research are proposed and possible ways are offered.
\end{abstract}

Keywords: active rectifier, DC/DC converter, soft switching

\section{INTRODUCTION}

The isolated DC/DC converters are frequently mentioned type of converters. They are high frequency operating power converters and the switching frequency is very important working condition for them. It is known, that increasing of their switching frequency causes reduction of their weight and size. But it is also well known that the switching losses in transistor switches are proportional to the switching frequency. Therefore, there is the request to reduce the switching losses. It can be achieved by using some kind of soft-switching technique. In this way high efficiency, small weight and size can be ensured. In Fig. 1, simplified idealized waveforms of soft switching of transistor switch are shown.
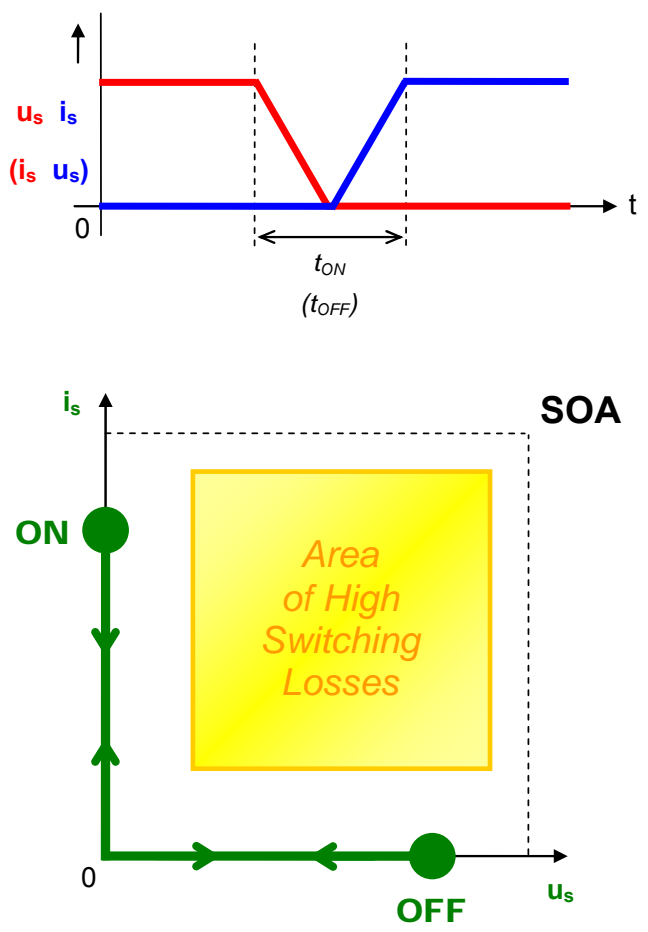

Fig. 1 Idealized waveforms of soft switching of transistor switch
The soft switching of transistor switches used in DC/DC converter can be partly achieved by using of DC/DC converter with secondary side active rectifier. This type of converter has one or more transistor switches on the secondary side. In Fig. 2, block diagram of this type of $\mathrm{DC} / \mathrm{DC}$ converter is shown.

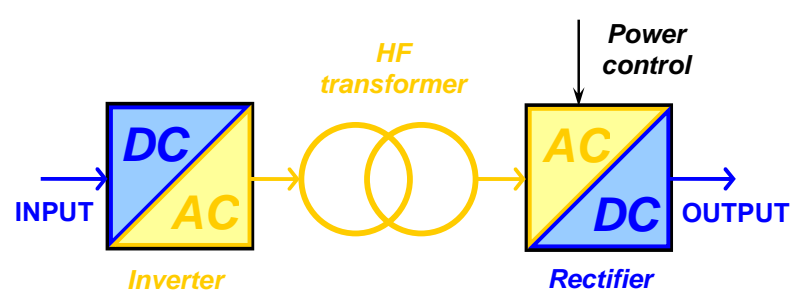

Fig. 2 Principled block diagram of isolated DC/DC converter with secondary side active rectifier

Few solutions of soft switching DC/DC converter with secondary side active rectifier were already published. The soft switching DC/DC converter with secondary side active rectifier controlled by one switch with secondary side snubber is presented in [1]-[4]. In this kind of converter topology the center tapped full wave controlled rectifier with one transistor switch is used. This kind of solution is very simple, low cost and easy applicable. Due to few devices in series with load current, conduction losses are small. The problem can occur only at soft switching of rectifier transistor switch, when big change of his duty cycle occurs. Further, in some cases it can be problem that switching frequency of rectifier switch is so high.

Soft switching DC/DC converter with secondary side active rectifier controlled by two switches with secondary side snubber is presented in [5]-[10]. In this kind of topology the center tapped full wave controlled rectifier with two transistor switches is used. This topology can be used in very high power applications. It can be very useful especially at high output voltage of the converter. The problem can occur only at soft switching of rectifier transistor switches, when big change of their duty cycle occurs. The disadvantage of this kind of topology is also 
that the symmetric passive snubber is quite complicated and consists of many devices.

The soft switching DC/DC converter with secondary side active rectifier controlled by two switches with primary side snubber is presented in [11]-[12]. In this converter topology the center tapped full wave controlled rectifier with two transistor switches is used. This type of topology is a simple and basic solution of $\mathrm{DC} / \mathrm{DC}$ converter with secondary side active rectifier controlled by two switches. It is easy applicable. Significant disadvantage is that primary side transistor switches turn off only at zero voltage, so when IGBTs are used as switches, tail current causes switching losses.

Another type of soft switching DC/DC converter with secondary side active rectifier controlled by two switches with primary side snubber is presented in [13]-[18]. In this kind of converter topology the full bridge controlled rectifier with two transistor switches is used. The main advantage is that at this kind of topology simple transformer with only one primary and one secondary winding is used. However, conduction losses of whole converter can be high because there are many devices in series with load current. The main disadvantage of this converter topology is that primary side transistor switches turn off only at zero voltage, so when IGBTs are used as switches, tail current causes turning off losses. Either way, every solution has some advantages and some disadvantages.

\section{ALREADY SOLVED PART OF RESEARCH TASK}

A chosen topology of DC/DC converter with secondary side active rectifier has one transistor switch on the secondary side. In Fig. 3, a circuit diagram of chosen converter topology is shown.

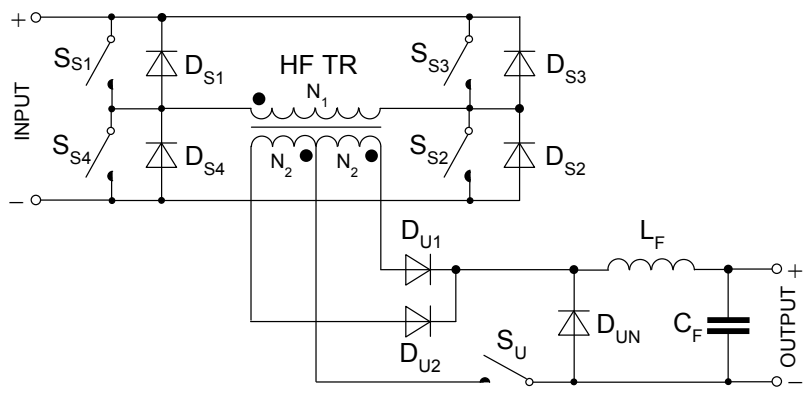

Fig. 3 Circuit diagram of chosen topology of DC/DC converter

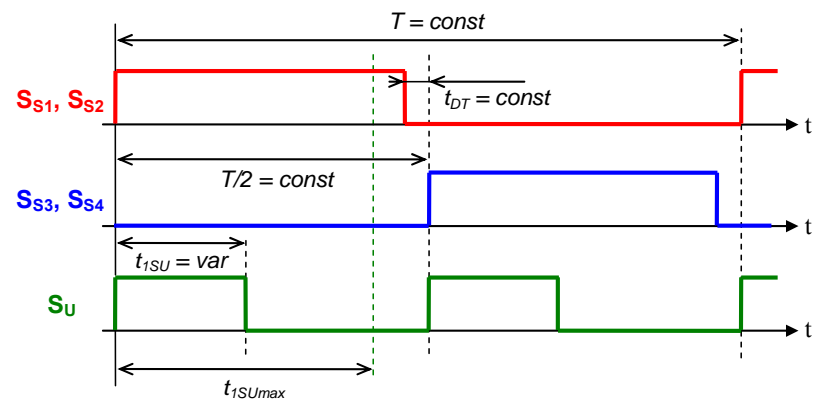

Fig. 4 Control algorithm of chosen topology of DC/DC converter
The chosen topology of $\mathrm{DC} / \mathrm{DC}$ converter with secondary side active rectifier is controlled by classical pulse width modulation. In Fig. 4, a respective control algorithm of chosen DC/DC converter topology is shown.

An operation principle of chosen DC/DC converter topology was already analyzed. Simplified analytical time waveforms of chosen converter topology were also already derived. They are shown in Fig. 5.

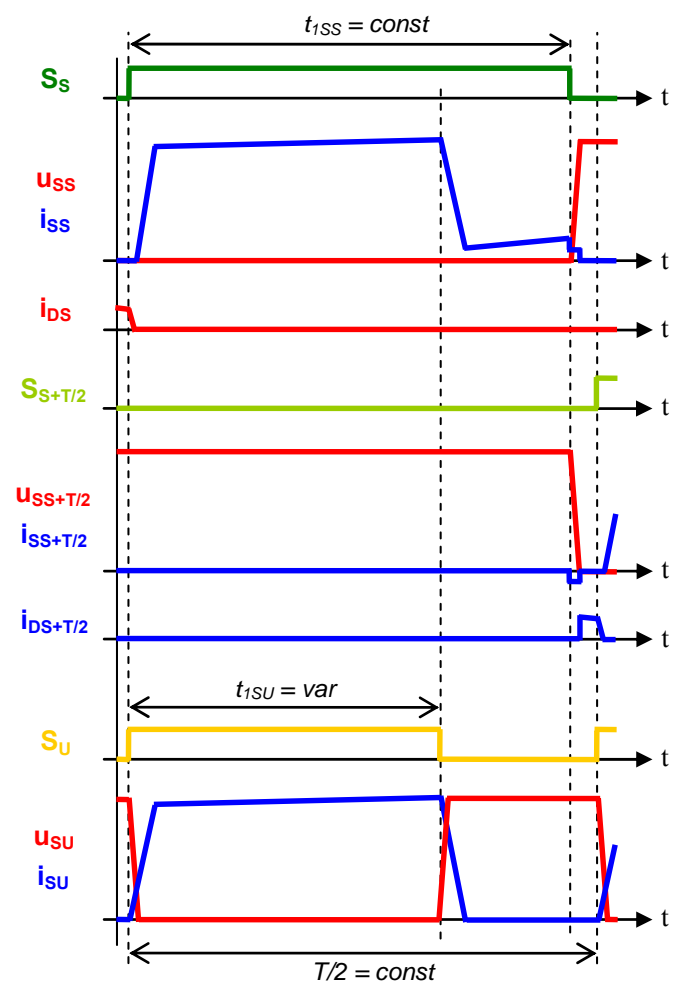

Fig. 5 Analytical waveforms of chosen topology of DC/DC converter

Equivalent circuit diagrams of all period time intervals were already derived, too. In Fig. 6, a simplified sequence from equivalent circuit diagrams of significant period time intervals is shown.

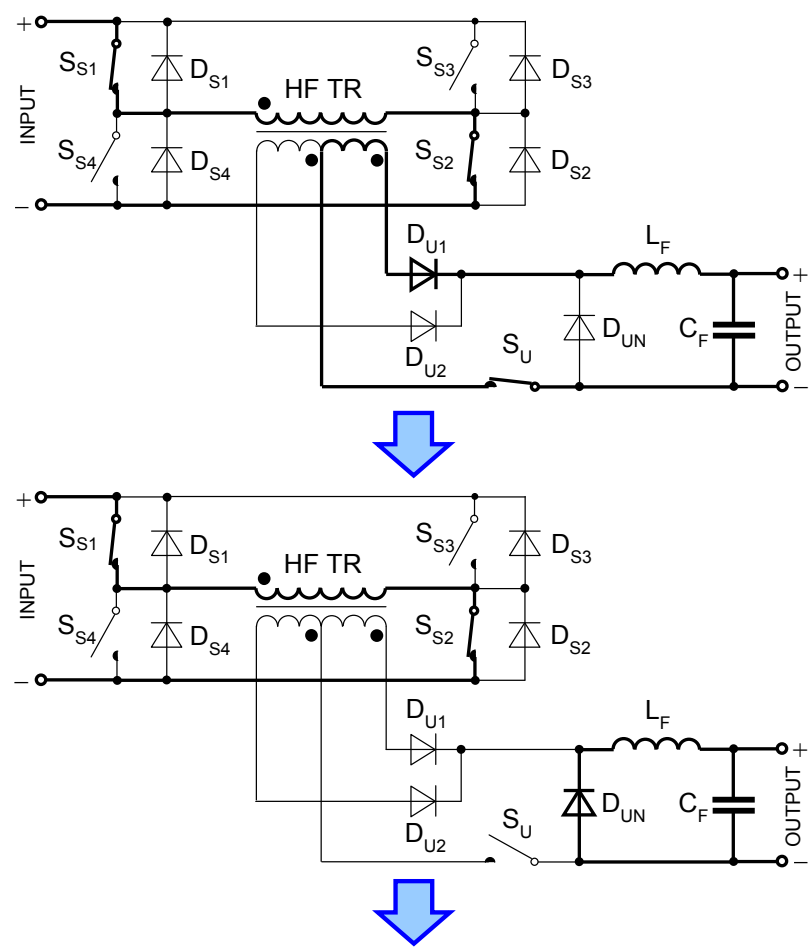



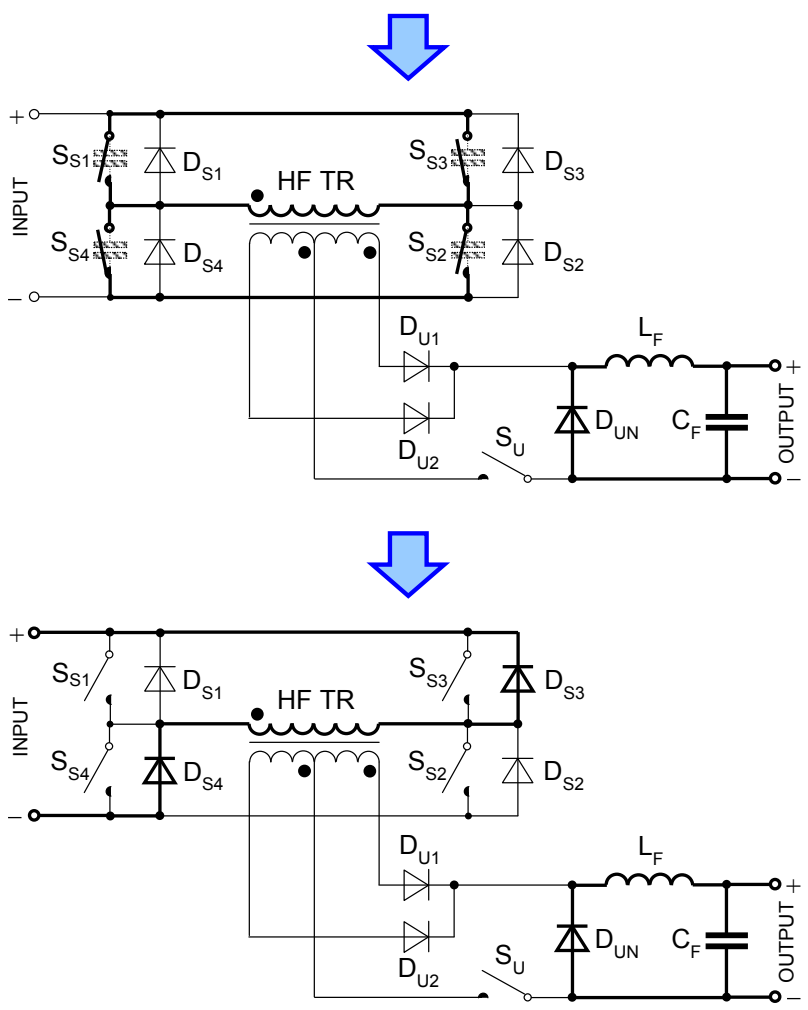

Fig. 6 Simplified sequence of equivalent circuit diagrams of chosen topology of DC/DC converter

From the operation principle analysis was obvious that the entirely soft switching DC/DC converter could be designed by application of some kind of auxiliary circuit. A principled circuit diagram of chosen converter topology containing auxiliary circuit (snubber) is shown in Fig. 7.

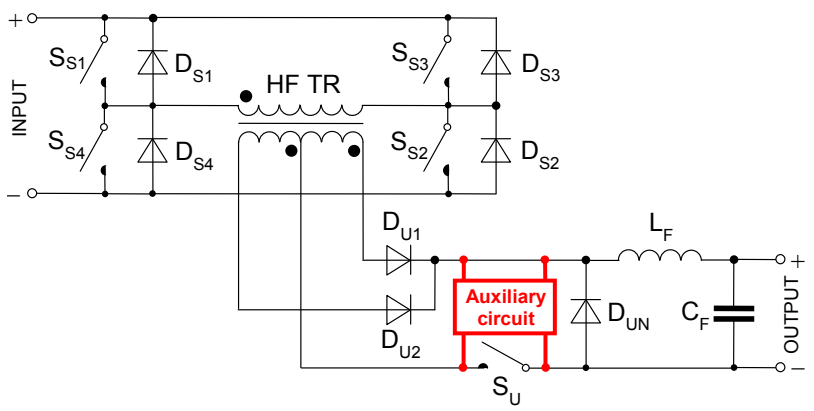

Fig. 7 Principled circuit diagram of chosen topology of DC/DC converter containing auxiliary circuit

\section{CURRENTLY SOLVED PART OF RESEARCH TASK}

To resolve this problem, a novel type of auxiliary circuit (snubber) was proposed. Therefore, a proposed topology of soft switching DC/DC converter with secondary side active rectifier has lossless auxiliary circuit. In Fig. 8, a circuit diagram of proposed soft switching converter topology is shown and in Fig. 9, a proposed control algorithm of this topology is shown.

A veritable function of proposed topology of soft switching DC/DC converter with secondary side active rectifier was verified by experimental measurement of

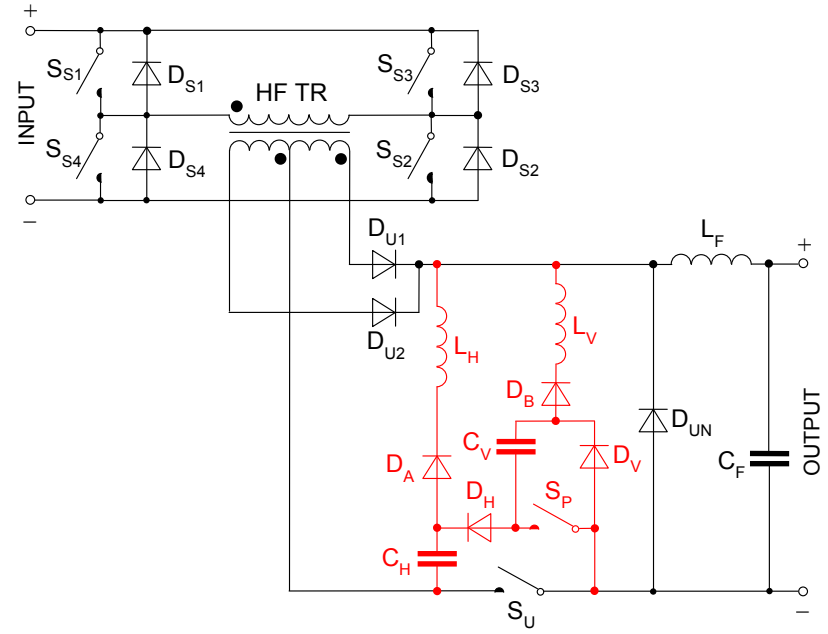

Fig. 8 Circuit diagram of proposed topology of soft switching $\mathrm{DC} / \mathrm{DC}$ converter

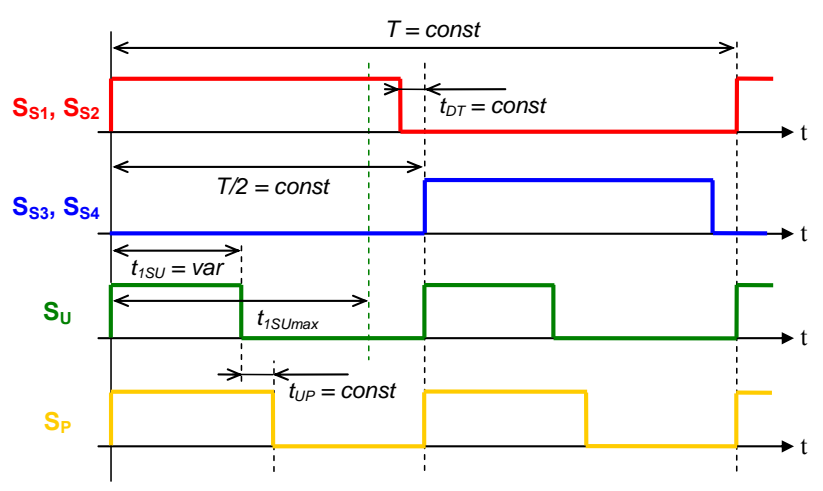

Fig. 9 Control algorithm of proposed topology of soft switching DC/DC converter

laboratory model. For this verification, the $3 \mathrm{~kW}$ laboratory model of this converter topology was built.

It was designed for rated input voltage of converter $\mathrm{U}_{\mathrm{IN}}=300 \mathrm{~V}$. The rated switching frequency of converter is $\mathrm{f}_{\mathrm{S}}=50 \mathrm{kHz}$. The rated turn's ratio of step down power transformer is $\mathrm{p}_{\mathrm{TR}}=5$.

A picture of this laboratory model is shown in Fig. 10. In the following, key experimental results are presented.

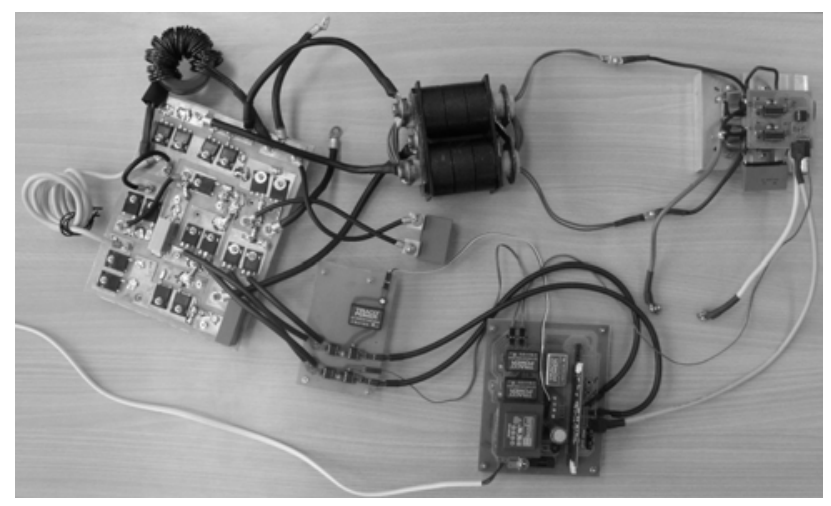

Fig. 10 Laboratory model of proposed topology of soft switching DC/DC converter

Experimentally measured time waveforms of collector-emitter voltage $\mathrm{u}_{\mathrm{Ss} 3}$ and collector current $\mathrm{i}_{\mathrm{Ss} 3}$ of 
inverter transistor switch $\mathrm{S}_{\mathrm{S} 3}$, collector-emitter voltage $\mathrm{u}_{\mathrm{Su}}$ and collector current $i_{S u}$ of rectifier transistor switch $S_{U}$, collector-emitter voltage $u_{S p}$ and collector current $i_{S p}$ of auxiliary circuit transistor switch $\mathrm{S}_{\mathrm{P}}$ are shown in Fig. 11 . From all these waveforms is obvious that in the proposed topology of soft switching DC/DC converter with secondary side active rectifier the soft switching is reliably achieved. The transistor switch $\mathrm{S}_{\mathrm{S} 3}$ turns on at zero voltage and also at zero current, and turns off at zero current. The transistor switches $\mathrm{S}_{\mathrm{U}}, \mathrm{S}_{\mathrm{P}}$ turn on at zero current, and turn off at zero voltage.

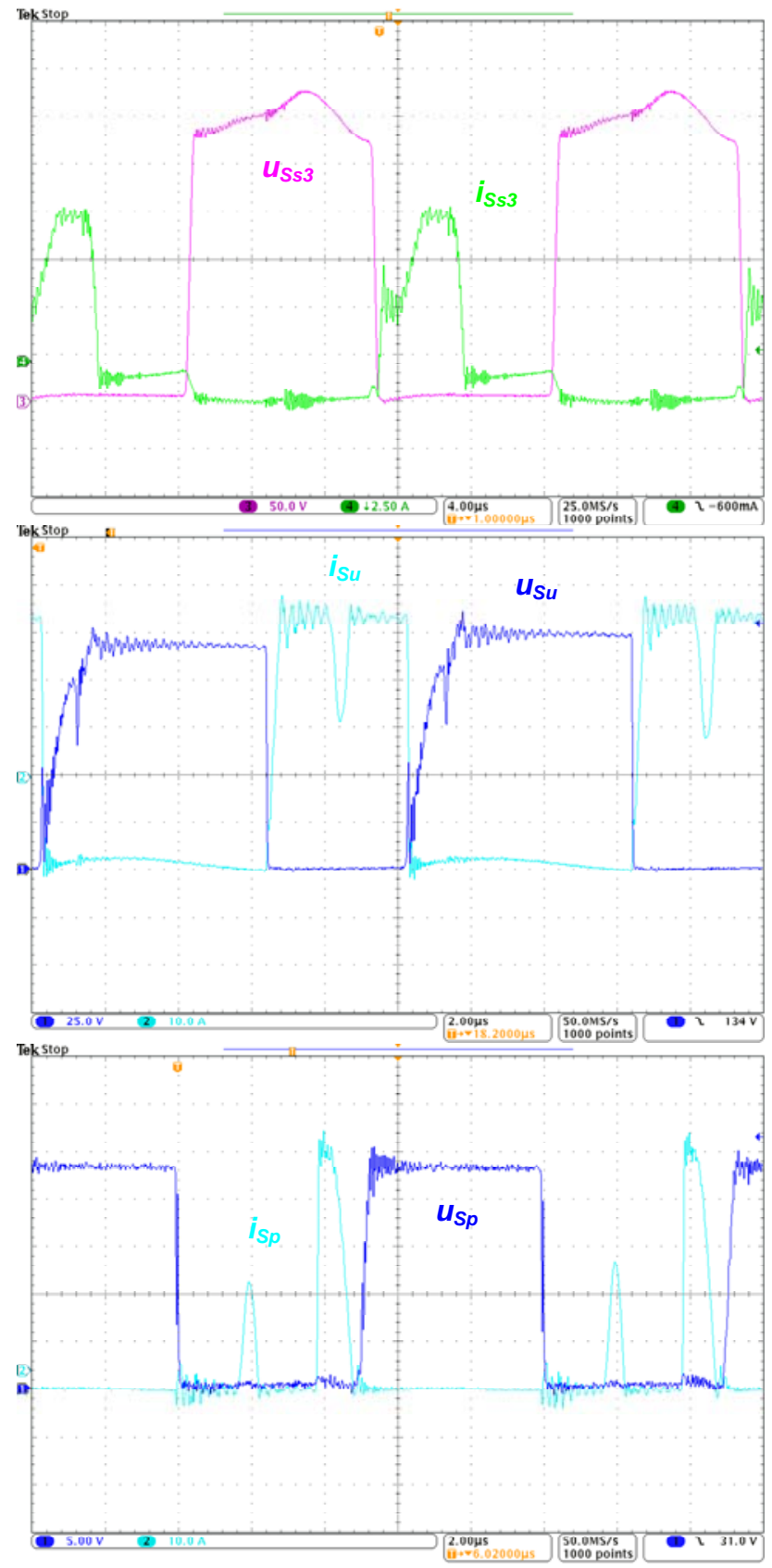

Fig. 11 Measured waveforms of voltage and current of transistor switches $\mathrm{S}_{\mathrm{S} 3}, \mathrm{~S}_{\mathrm{U}}, \mathrm{S}_{\mathrm{P}}$

\section{CONCLUSIONS}

Soft switching of all transistor switches is reliably ensured. In the future, the laboratory model of proposed topology of soft switching DC/DC converter should be optimized, the analytical time waveforms of this converter topology and the equivalent circuit diagrams of all period time intervals should be derived. Also, another type of auxiliary circuit could be proposed. By this way, the complexity of auxiliary circuit could be reduced.

The proposed auxiliary circuit could consist of passive devices like capacitor, inductor, diode, and also active devices like transistor. Hence, finally proposed auxiliary circuit can be passive or active. Generally, passive circuit is simpler than active circuit, but active circuit can be more effective and in many situations more convenient. It must be taken into consideration that control algorithm of active circuit can significantly influence the resultant function and effect. Therefore, a correct combination of auxiliary circuit and control algorithm is very significant.

The load range in which the soft switching of all switches is reliably ensured should be taken into consideration, too.

\section{ACKNOWLEDGMENTS}

This work was supported by Slovak Research and Development Agency under project APVV-0185-10 and by Scientific Grant Agency of the Ministry of Education of Slovak Republic under the contract VEGA No. 1/0464/15. The work was supported by FEI-2015-3.

\section{REFERENCES}

[1] DUDRIK, J. - RUSCIN, V.: Voltage fed zerovoltage zero-current switching PWM DC-DC converter, 13th Power Electronics and Motion Control Conference, Poznan, pp. 295-300, 2008.

[2] PERDUL'AK, J. - BODOR, M.: Novel Zero-Voltage and Zero-Current Switching Full-Bridge PWM Converter Using Simple Secondary Active Clamp Circuit, 12th International PhD Workshop, Owd, pp. 147-152, 2010.

[3] DUDRIK, J.: DC-DC converter with controlled rectifier with one active switch, EE journal, Vol. 20, No. 3, pp. 12-14, 2014.

[4] DUDRIK, J. - RUSCIN, V.: ZVZCS PWM DC-DC converter with controlled output rectifier, Acta Electrotechnica et Informatica, Vol. 10, No. 1, pp. 12-17, 2010.

[5] DUDRIK, J. - RUŠČIN, V. - BODOR, M. - TRIP, D. N. - S̆PÁNIK, P.: Soft switching full-bridge PWM DC/DC converter using secondary snubber, Journal of Electrical and Electronics Engineering, Vol. 2, No. 1, pp. 147-150, 2009.

[6] DUDRIK, J. - BODOR, M. - PASTOR, M.: SoftSwitching Full-Bridge PWM DC-DC Converter with Controlled Output Rectifier and Secondary Energy Recovery Turn-Off Snubber, IEEE Transactions on Power Electronics, Vol. 29, No. 8, pp. 4116-4125, 2014.

[7] RUŠČIN, V. - DUDRIK, J.: Soft switching DC/DC converter using auxiliary circuits, Journal of Electrical and Electronics Engineering, Vol. 1, No. 1, pp. 242-245, 2008. 
[8] DUDRIK, J. - BODOR, M. - TRIP, D. N.: Operation analysis of soft switching PWM DC-DC converter with secondary snubber, Communications, Vol. 15, No. 3, pp. 6-12, 2013.

[9] DUDRIK, J. - BODOR, M.: Novel soft switching DC/DC converter with controlled output rectifier, 15th International Power Electronics and Motion Control Conference, Novi Sad, pp. DS1b.13-1DS1b.13-5, 2012.

[10] DUDRIK, J. - BODOR, M. - RUSCIN, V.: Zerovoltage and zero-current switching DC-DC converter with controlled output rectifier, 14th International Power Electronics and Motion Control Conference, Ohrid, pp. T1-39-T1-44, 2010.

[11] DUDRIK, J. - ŠEPELA, J.: Soft Switching Current Mode Controlled DC-DC Converter with Secondary Switches, Electrical Drives and Power Electronics International Conference, Dubrovnik, pp. E05_98, 2005.

[12] DUDRIK, J.: Soft-switching PS-PWM DC-DC converter for arc welding, Acta Electrotechnica et Informatica, Vol. 6, No. 3, pp. 1-4, 2006.

[13] MISHIMA, T. - AKAMATSU, K. - NAKAOKA, M.: A High Frequency-Link Secondary-Side PhaseShifted Full-Range Soft-Switching PWM DC-DC Converter with ZCS Active Rectifier for EV Battery Chargers, IEEE Transactions on Power Electronics, Vol. 28, No. 12, pp. 5758-5773, 2013.

[14] SUZUOKA, K. - MOISSEEV, S. - GAMAGE, L. SOSHIN, K. - NISHIDA, K. - NAKAOKA, M.: Boost transformer linked full bridge softcommutation DC-DC power converter with secondary-side phase-shifted PWM rectifier switches, 29th Annual Conference of the IEEE Industrial Electronics Society, pp. 49-54, Vol. 1, 2003.

[15] MISHIMA, T. - AKAMATSU, K. - NAKAOKA, M.: A zero voltage and zero current soft switching PWM dc-dc converter with secondary-side phaseshifting active rectifier, Energy Conversion Congress and Exposition, Raleigh, pp. 2544-2551, 2012.

[16] AL, M. A. - NAKAMURA, M. - SATO, S. NAKAOKA, M.: High frequency link transformer secondary side control DC-DC power converter, Power Conversion Conference, Osaka, pp. 593-596, Vol. 2, 2002.

[17] MISHIMA, T. - AKAMATSU, K. - NAKAOKA, M.: Analysis, design and evaluations of a soft switching PWM DC-DC converter with phase shiftcontrolled ZCS active hybrid rectifier, 38th Annual Conference on IEEE Industrial Electronics Society, Montreal, pp. 244-249, 2012.

[18] AHMED, N. A. - MIYATAKE, M. - NISHIMURA, K. - HYUN-WOO, L. - NAKAOKA, M.: Novel High Frequency Planner Transformer Linked Soft Switching DC-DC Power Converter with Secondary Side-Phase Shifted PWM Active Rectifying Switches, International Conference on Power Electronics and Drives Systems, Kuala Lumpur, pp. 129-135, 2005.

Received July 1, 2016, accepted September 15, 2016

\section{BIOGRAPHIES}

Róbert Žatkovič was born in Košice, Slovakia, in 1990. He received the M.Sc. degree in electrical engineering from the Technical University of Košice, Slovakia, in 2014. He is currently a full-time Ph.D. student at the Department of Electrical Engineering and Mechatronics, Technical University of Košice, Slovakia. His primary interest is power electronics. His field of research includes high frequency DC/DC converters and soft switching techniques.

Jaroslav Dudrik received the M.Sc. and Ph.D. degrees in electrical engineering from the Technical University of Košice, Slovakia, in 1976 and 1987, respectively. He is currently a full professor at the Department of Electrical Engineering and Mechatronics, Technical University of Košice. His primary interest is power electronics. His field of research includes dc-to-dc converters, high-power softswitching converters, converters for renewable energy sources, and control theory of converters.

Nistor Daniel Trip graduated in 1993 Applied Electronics specialization at Technical University of ClujNapoca, Romania, and he obtained the Ph.D. degree in Electronics and Telecommunications Engineering from the University "Politehnica" of Timisoara, Romania, in 2004. Since 1993, he is with the Department of Electronics and Telecommunications, University of Oradea, Romania, where he is currently university professor. His research interests include industrial and power electronics, DC-DC converters, resonant and softswitching converters, as well as applications with microcontrollers and digital signal processors. 